\title{
Spillover of Cytokines and Reactive Oxygen Species in Ventilator-Induced Lung Injury Associated With Inflammation and Apoptosis in Distal Organs
}

\author{
Yung-Yang Liu MD, Chi-Huei Chiang MD, Chiao-Hui Chuang MSc, \\ Shiou-Ling Liu MSc, Yi-Han Jheng MSc, and Jay H Ryu MD
}

\begin{abstract}
BACKGROUND: The mechanism between ventilator-induced lung injury (VILI) and multiple organ injury is unclear. The aim of our study was to investigate the mechanisms of VILI-induced distal organ injury. METHODS: VILI was induced in rat lungs with high tidal volume $\left(V_{T}\right)$ ventilation of $40 \mathrm{~mL} / \mathrm{kg}$ for $6 \mathrm{~h}$. Rats with low $V_{T}$ ventilation of $6 \mathrm{~mL} / \mathrm{kg}$ served as controls. Inflammatory and apoptotic indices in lung and distal organs were assessed. RESULTS: VILI increased lung weight, airway pressure, inflammation, and apoptotic pathologic changes without

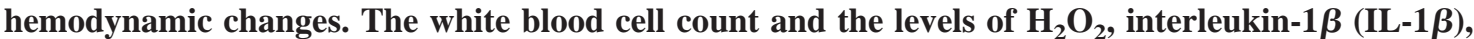
tumor necrosis factor alpha, and macrophage inflammatory protein-2 in bronchoalveolar lavage fluid were higher in the VILI group compared with the control group. $\mathrm{H}_{2} \mathrm{O}_{2}$, IL-1 $\beta$, and tumor necrosis factor alpha in blood from the left ventricle were up-regulated. $\mathrm{H}_{2} \mathrm{O}_{2}$, IL-1 $\beta$, tumor necrosis factor alpha, macrophage inflammatory protein-2, c-Jun N-terminal kinase, p38, nuclear factor kappa B, and caspase-3 in lung, heart, liver, and kidney tissues in the VILI group were up-regulated. Furthermore, the apoptotic score for the kidneys was higher than those for other distal organs in the VILI group. CONCLUSIONS: High $V_{T}$ ventilation induces VILI and is associated with inflammation and apoptosis in distal organs. Up-regulation of reactive oxygen species and cytokines in VILI is associated with systemic inflammatory responses. Kidney tissue appears to be more vulnerable than heart and liver tissues following VILI. Key words: apoptosis; inflammation; reactive oxygen species; ventilator-induced lung injury. [Respir Care 2014;59(9):1422-1432. (C) 2014 Daedalus Enterprises]
\end{abstract}

\section{Introduction}

In patients with ARDS, the application of low tidal volume $\left(\mathrm{V}_{\mathrm{T}}\right)$ ventilatory strategies has been shown to de-

Dr Liu, Dr Chiang, Ms Chuang, and Ms Liu are affiliated with the Section of Respiratory Therapy, Department of Chest Medicine, Taipei Veterans General Hospital, Taipei, Taiwan. Dr Liu is also affiliated with the Institute of Clinical Medicine, and Dr Chiang is also affiliated the Institute of Emergency and Critical Care Medicine and the Faculty of Medicine, School of Medicine, National Yang-Ming University, Taipei, Taiwan. Dr Chiang is also affiliated with the Department of Medicine, National Defense Medical Center, Taipei, Taiwan. Dr Ryu is affiliated with the Division of Pulmonary and Critical Care Medicine, Mayo Clinic, Rochester, Minnesota.

This work was supported by Taipei Veterans General Hospital grants 101DHA0100665, 101DHA0100079, 100DHA0100130, and 99DHA0100412 and National Science Council grants NSC97-2314-B- crease mortality. ${ }^{1}$ Despite improvement in outcome due to lung-protective ventilation using low $\mathrm{V}_{\mathrm{T}}$, the mortality rate from ARDS remains unacceptably high. A recent international study reported an ICU mortality rate of $60.2 \%$ in subjects with ARDS. ${ }^{2}$ The majority of patients with ARDS do not die from irreversible hypoxemia, but rather from multiple organ failure, ${ }^{2-5}$ suggesting the hypothesis that

\footnotetext{
075-045, NSC98-2314-B-075-036, and NSC99-2314-B-075-034-MY2. The authors have disclosed no conflicts of interest.

Correspondence: Chi-Huei Chiang MD, Division of Pulmonary Immunology and Infectious Diseases, Chest Department, Taipei Veterans General Hospital, No. 201, Section 2, Shih-Pai Road, Taipei, Taiwan. E-mail: chiang01@vghtpe.gov.tw, chiang1990@gmail.com.
}

DOI: $10.4187 /$ respcare. 02992 
mechanical ventilation, the mainstay of ARDS treatment, could itself enhance the inflammation and worsen multisystem injury. ${ }^{6}$

Inappropriate mechanical ventilation can initiate or exacerbate lung injury, leading to ventilator-induced lung injury (VILI) as a result of volutrauma ${ }^{7}$ and biotrauma. ${ }^{8}$ Animal studies have demonstrated that high $\mathrm{V}_{\mathrm{T}}$ ventilation leads to increased neutrophil infiltration, activation of inflammatory cytokines, pulmonary inflammation, and diffuse alveolar damage via activation of the mitogen-activated protein kinase (MAPK) and nuclear factor kappa B (NF-KB) pathways. ${ }^{9}$ Thus, VILI in animal models resembles the clinical features of ARDS. ${ }^{10,11}$ Hyperventilation of a single lung in an isolated rat lung model leads to production of pro-inflammatory tumor necrosis factor alpha, increased permeability, and injury to the contralateral lung via circulating mediators, that is, biotrauma. ${ }^{12}$ Over the last decade, this biotrauma ${ }^{6,13-17}$ has been proposed as the mechanism underlying multiple organ injury in patients with ARDS. This hypothesis has not been well explored and requires further investigation.

In this study, we explored whether VILI could induce distal organ injury and the potential biomolecular mechanisms of this injury. This framework may be useful in guiding the development of novel therapeutic strategies that ultimately improve the outcome of patients with ARDS who are undergoing mechanical ventilation.

\section{Methods}

\section{Animals}

This study was approved by the Taipei Veterans General Hospital Subcommittee on Research Animal Care. Virus-free Sprague-Dawley rats (weighing between 250 and $300 \mathrm{~g}$ ) were obtained from Charles River Laboratories (Wilmington, Massachusetts).

\section{Experimental Protocols}

Male Sprague-Dawley rats were anesthetized by intraperitoneal injection of sodium pentobarbital (20-25 mg) while breathing room air. PE 240 tubing (infusion therapy system, BD Medical, Sandy, Utah) was inserted into the trachea and connected to a ventilator (model 55-7058, Harvard Apparatus, Holliston, Massachusetts). We used our established ventilator protocol in the rat model of VILI as described previously. ${ }^{18}$ The rats were then randomly assigned into 2 groups ( $n=7$ for each group) by using a random-number table and ventilated for $6 \mathrm{~h}$ with either a high $\mathrm{V}_{\mathrm{T}}$ of $40 \mathrm{~mL} / \mathrm{kg}$ or a low $\mathrm{V}_{\mathrm{T}}$ of $6 \mathrm{~mL} / \mathrm{kg}$. A PEEP of $2 \mathrm{~cm} \mathrm{H}_{2} \mathrm{O}$ was applied to all groups. End-tidal carbon dioxide pressure was monitored intermittently with a microcapnograph (Columbus Instruments, Columbus, Ohio)

\section{QUICK LOOK}

\section{Current knowledge}

Ventilator-induced lung injury (VILI) caused by aggressive ventilation characterized by high tidal volumes $\left(\mathrm{V}_{\mathrm{T}}\right)$ and low end-expiratory pressures is implicated in the development of multiple organ failure and mortality. The exact mechanism of distal organ failure is unclear.

\section{What this paper contributes to our knowledge}

High $\mathrm{V}_{\mathrm{T}}$ ventilation produces VILI and is associated with inflammation and apoptosis in distal organs, triggered by spillover of the reactive oxygen species and cytokines into the circulation. This systemic inflammation and apoptosis is associated with up-regulation of c-Jun N-terminal kinase, p38, nuclear factor kappa B, and caspase- 3 in the lung, heart, liver, and kidney.

and was kept between 35 and $45 \mathrm{~mm} \mathrm{Hg}$ by adjusting the breathing frequency of the ventilator. The femoral artery and vein were cannulated. Tracheal airway pressure and arterial blood pressure were continuously monitored with a polygraph (Gould Instrument System, Cleveland, Ohio). During the period of ventilator use, intraperitoneal sodium pentobarbital at $0.05 \mathrm{mg} / \mathrm{g}$ was administered every $30 \mathrm{~min}$, and the intraperitoneally administered anesthesia fluid was sufficient to correct for hypovolemia. After $6 \mathrm{~h}$, the chest was opened by an incision in the left border of the sternum, arterial blood was withdrawn from the left heart ventricle, and the blood serum was stored in a $-80^{\circ} \mathrm{C}$ refrigerator for cytokine and $\mathrm{H}_{2} \mathrm{O}_{2}$ measurement.

\section{Bronchoalveolar Lavage Fluid}

The lungs were removed en bloc, and tubing was inserted into the trachea and secured. The right lung was clamped at the bronchus to prevent lavage fluid from entering the right lung. The lungs were lavaged by instilling normal saline at $2.5 \mathrm{~mL}$ twice in the left lung. Recovered lavage samples were centrifuged at $1,500 \times \mathrm{g}$ at room temperature for $10 \mathrm{~min}$. The white blood cell count in bronchoalveolar lavage fluid (BALF) was determined using a hemocytometer. An enzyme-linked immunosorbent assay was performed to measure the concentration of cytokines, including macrophage inflammatory protein-2 (MIP-2), interleukin-1 $\beta$ (IL-1 $\beta$ ), and tumor necrosis factor alpha, in the supernatant. ${ }^{11}$

\section{$\mathrm{H}_{2} \mathrm{O}_{2}$ Assay}

BALF and arterial blood from the left ventricle were centrifuged at $1,000 \times \mathrm{g}$ within $30 \mathrm{~min}$, and the superna- 
tant was collected. $\mathrm{H}_{2} \mathrm{O}_{2}$ reaction mixture $(50 \mu \mathrm{l})$ containing $46 \mu \mathrm{l}$ of assay buffer, $2 \mu \mathrm{l}$ of OxiRed probe solution (BioVision, Milpitas, California), and $2 \mu \mathrm{l}$ of horseradish peroxidase solution (BioVision) was added, followed by incubation for $10 \mathrm{~min}$. Absorbance was read at $570 \mathrm{~nm}$ (SpectraMax M5, Molecular Devices, Sunnyvale, California). Concentration was calculated based on $\mathrm{H}_{2} \mathrm{O}_{2}$ standard curves.

\section{Western Blot Analysis}

Lung, heart, liver, and kidney tissues were homogenized using lysis buffer containing protease inhibitor mixture and phosphatase inhibitor mixture (both from Roche Applied Science, Indianapolis, Indiana). Total protein extracts were separated on $10 \%$ sodium dodecyl sulfate-polyacrylamide gel and electrotransferred onto polyvinylidene fluoride membrane (Millipore, Billerica, Massachusetts). The membrane was blocked with 5\% nonfat dry milk in Trisbuffered saline containing $0.1 \%$ Tween 20 for $1 \mathrm{~h}$. Antibodies against phosphorylated p44/42 MAPK (extracellular signal-regulated kinases (ERK) 1 and 2), phosphorylated stress-activated protein kinase/c-Jun N-terminal kinase (JNK), and phosphorylated p38 MAPK (1:1,000 dilution; Cell Signaling Technology, Beverly, Massachusetts) were used. Antibodies against glyceraldehyde-3-phosphate dehydrogenase (1:10,000 dilution; LabFrontier, Seoul, Korea), JNK (1:1,000 dilution; Santa Cruz Biotechnology, Santa Cruz, California), caspase-3 (1:2,000 dilution; Cell Signaling Technology), phosphorylated AKT serine/threonine kinase (1:1,000 dilution; Cell Signaling Technology), AKT (1:1,000 dilution; Cell Signaling Technology), MIP-2 (1:1,000 dilution; Abcam, Cambridge, Massachusetts), IL-1 $\beta$ (1:1,000 dilution; Abcam), and tumor necrosis factor alpha (1:1,000 dilution; Abcam) were used. Horseradish peroxidase-conjugated anti-rabbit secondary antibodies were used (1:10,000 dilution; Jackson ImmunoResearch Laboratories, West Grove, Pennsylvania). Visualization was performed by enhanced chemiluminescence (Visual Protein Biotechnology, Taipei, Taiwan). Protein bands were quantified using the Kodak 1D image analysis software package (version 3.5, Eastman Kodak, Rochester, New York).

\section{NF-KB Analysis of Nuclear Protein}

Lung tissue was homogenized with a Dounce tissue homogenizer in $5 \mathrm{~mL}$ of solution containing $0.6 \%$ Nonidet P-40, $150 \mathrm{mM} \mathrm{NaCl}, 10 \mathrm{mM}$ 4-(2-hydroxyethyl)-1-piperazineethanesulfonic acid ( $\mathrm{pH}$ 7.9), $1 \mathrm{mM}$ ethylenediaminetetraacetic acid, and $0.5 \mathrm{mM}$ phenylmethylsulfonyl fluoride. The homogenates were centrifuged for $30 \mathrm{~s}$ at 2,000 rpm, and the supernatants were collected and centrifuged for $5 \mathrm{~min}$ at $5,000 \mathrm{rpm}$. The pelleted nuclei were resuspended at $4^{\circ} \mathrm{C}$ in $300 \mu \mathrm{L}$ of solution containing $25 \%$ glycerol, $20 \mathrm{mM}$ 4-(2-hydroxyethyl)-1-piperazineethanesulfonic acid ( $\mathrm{pH} 7.9$ ), $420 \mathrm{mM} \mathrm{NaCl}, 1.2 \mathrm{mM} \mathrm{MgCl}{ }_{2}$, $0.2 \mathrm{mM}$ ethylenediaminetetraacetic acid, $0.5 \mathrm{mM}$ dithiothreitol, $0.5 \mathrm{mM}$ phenylmethylsulfonyl fluoride, $2 \mathrm{mM}$ benzamidine, $5 \mu \mathrm{g} / \mathrm{mL}$ pepstatin $\mathrm{A}, 5 \mu \mathrm{g} / \mathrm{mL}$ leupeptin, and $5 \mu \mathrm{g} / \mathrm{mL}$ aprotinin and incubated on ice for $20 \mathrm{~min}$. Samples were centrifuged at $15,000 \mathrm{rpm}$ for $1 \mathrm{~min}$. The total protein concentration in the extract was determined using a bicinchoninic acid protein assay (Pierce, Rockford, Illinois). The membrane was blocked for $1 \mathrm{~h}$. Anti-NF-KB and anti-proliferating cell nuclear antigen antibodies (both at 1:1,000 dilution; both from Cell Signaling Technology) were diluted in Tris-buffered saline containing $0.1 \%$ Tween 20 and incubated overnight at $4^{\circ} \mathrm{C}$. Horseradish peroxidase-conjugated anti-rabbit secondary antibodies were used (1:10,000 dilution) at room temperature for $1 \mathrm{~h}$. Visualization was performed by enhanced chemiluminescence. The protein bands on the destained gels were quantified using the Kodak 1D image analysis software package (version 3.5). Anti-proliferating cell nuclear antigen antibody was used as a loading control to correct the pixel values for NF-KB.

\section{Terminal Deoxynucleotidyl Transferase dUTP Nick End Labeling Stain for Apoptosis}

Lung, heart, liver, and kidney tissue slides coated with poly-L-lysine (Sigma, St. Louis, Missouri) were deparaffinized and rehydrated using xylene and ethanol. The background was diminished by preincubating samples with $3 \%$ bovine serum albumin and $20 \%$ normal bovine serum in phosphate-buffered saline for $30 \mathrm{~min}$ at room temperature. The specimens were then exposed for $1 \mathrm{~h}$ at $37^{\circ} \mathrm{C}$ in a moist chamber to a labeling mixture containing 0.135 unit/mL calf terminal deoxynucleotidyl transferase, 0.0044 $\mathrm{nmol} / \mathrm{mL}$ digoxigenin-11-2'-deoxyuridine 5 '-triphosphate, and $1 \mathrm{mM}$ cobalt chloride in distilled water. Following washing, the specimens were resaturated in $3 \%$ bovine serum albumin and 20\% normal sheep serum. They were then treated for $1 \mathrm{~h}$ at room temperature with peroxidaselabeled anti-digoxigenin sheep Fab fragment (dilution of 1.25 units $/ \mathrm{mL}$ peroxidase), washed again, and subjected to a $0.05 \% 3,3^{\prime}$-diaminobenzidine tetrahydrochloride color reaction (Dako, Carpinteria, California). Analysis was performed with an Eclipse 80i microscope (Nikon, Tokyo, Japan) using Image-Pro Plus 5.0 (Media Cybernetics, Rockville, Maryland). The cells with terminal deoxynucleotidyl transferase dUTP nick end labeling (TUNEL)-positive staining in nuclei were counted in groups of 100 cells on the 3 slides of immunohistochemical stain for each animal tissue. Two pathologists blinded to the experimental conditions assessed morphology. 
Table 1. Arterial Blood Pressure and Heart Rate in the Control and VILI Groups

\begin{tabular}{|c|c|c|c|c|}
\hline \multirow{2}{*}{ Group } & \multicolumn{2}{|c|}{$\begin{array}{l}\text { Systolic Blood Pressure } \\
(\mathrm{mm} \mathrm{Hg})\end{array}$} & \multicolumn{2}{|c|}{$\begin{array}{l}\text { Heart Rate } \\
\text { (beats/min) }\end{array}$} \\
\hline & Baseline & $6 \mathrm{~h}$ & Baseline & $6 \mathrm{~h}$ \\
\hline Control $(n=7)$ & $118.4 \pm 7.0$ & $110 \pm 2.8$ & $324 \pm 6$ & $266 \pm 28$ \\
\hline VILI $(n=7)$ & $124.7 \pm 23.2$ & $107 \pm 9.8$ & $389 \pm 43$ & $268 \pm 39$ \\
\hline \multicolumn{5}{|c|}{$\begin{array}{l}\text { Values are presented as mean } \pm \text { SD. No significant differences in the values at baseline and } \\
6 \mathrm{~h} \text { of ventilation in the control and VILI groups were found. } \\
\text { VILI = ventilator-induced lung injury }\end{array}$} \\
\hline
\end{tabular}

\section{Lung Histopathology}

Upon completion of the experiments, the lungs were dissected and fixed immediately in $10 \%$ neutral buffered formalin. The right lower lobes were dehydrated through a graded series of alcohol, cleared in xylene, embedded in paraffin, and stained with hematoxylin and eosin. Three slides from each animal were evaluated for a total of 6 rats per group. The lung injury score was scaled and evaluated as described previously. ${ }^{11,18,19}$

\section{Statistical Analysis}

Systat 10.0 (Systat Software, San Jose, California) was used for statistical analysis. The normal (or gaussian) distribution was found in the distribution of values of various parameters in all groups. Comparisons of the levels of $\mathrm{H}_{2} \mathrm{O}_{2}$, tumor necrosis factor alpha, IL-1 $\beta$, MIP-2, caspase-3, phosphorylated AKT, MAPK, and NF-KB and percent of TUNEL-positive tissue in all groups (lung, heart, liver, kidney, and serum) were conducted by 2 -way repeated-measures analysis of variance. Comparison between baseline and post-VILI values of arterial blood pressure, heart rate, wet/dry lung weight, total wet lung weight/body weight ratio, $\mathrm{H}_{2} \mathrm{O}_{2}$, tumor necrosis factor alpha, IL-1 $\beta$, and MIP-2 in lavage fluid and the injury scores of the pathologic changes in the control and VILI groups was conducted using the unpaired Student $t$ test. Values are expressed as mean $\pm \mathrm{SD} . P<.05$ was considered statistically significant.

\section{Results}

\section{Hemodynamics}

There was no significant statistical difference in hemodynamics between the groups at the beginning versus the end of $6 \mathrm{~h}$ of mechanical ventilation (Table 1).

\section{Pulmonary Edema, Lung Compliance, and Cell Count in BALF}

The wet/dry ratio, BALF cell counts, changes in peak airway pressure, and lung/body weight ratio in the VILI group were higher than those in the control group (Table 2).

\section{Reactive Oxygen Species}

The $\mathrm{H}_{2} \mathrm{O}_{2}$ levels in BALF (Fig. 1A), arterial blood from the left ventricle, and lung, heart, liver, and kidney tissues in the VILI group were significantly higher than those in the control group (Fig. 1B). These data indicate up-regulation of reactive oxygen species in lungs, arterial blood, and distal organs during VILI.

\section{Cytokines}

The levels of MIP-2, IL-1 $\beta$, and tumor necrosis factor alpha in BALF were significantly increased in the VILI group compared with those in the control group (Fig. 2, $\mathrm{A}-\mathrm{C})$. Furthermore, the levels of tumor necrosis factor alpha and IL- $1 \beta$ in blood and lung, heart, liver, and kidney tissues were significantly higher in the VILI group compared with the control group (Fig. 2, D and E). In the VILI group, the tumor necrosis factor alpha levels in kidney tissue and serum were higher than those in lung and liver

Table 2. Wet/Dry Lung Ratio, Total BALF White Blood Cell Count, $\Delta \mathrm{P}$, and Total Wet Lung/Body Weight Ratio in the Control and VILI Groups

\begin{tabular}{|c|c|c|c|c|}
\hline Group & Wet/Dry Lung & $\begin{array}{l}\text { White Blood } \\
\text { Cell Count } \\
(\mu \mathrm{L})\end{array}$ & $\begin{array}{c}\Delta \mathrm{P} \\
\left(\mathrm{cm} \mathrm{H} \mathrm{H}_{2} \mathrm{O}\right)\end{array}$ & $\begin{array}{l}\text { Total Wet Lung/ } \\
\text { Body Weight }\end{array}$ \\
\hline Control $(n=7)$ & $4.31 \pm 0.09$ & $146.9 \pm 21.3$ & $0.57 \pm 0.54$ & $0.0043 \pm 0.0002$ \\
\hline VILI $(n=7)$ & $5.75 \pm 1.25^{*}$ & $754.7 \pm 212.6^{*}$ & $3.71 \pm 1.25^{*}$ & $0.0071 \pm 0.0019^{*}$ \\
\hline \multicolumn{5}{|c|}{$\begin{array}{l}\text { Values are presented as mean } \pm \mathrm{SD} \text {. } \\
* P<.05 \text { compared with the control }(6 \mathrm{~h}) . \\
\text { BALF = bronchoalveolar lavage fluid } \\
\text { VILI = ventilator-induced lung injury } \\
\Delta \mathrm{P}=\text { intratracheal pressure after } 6 \mathrm{~h} \text { of ventilation }- \text { baseline intratracheal pressure }\end{array}$} \\
\hline
\end{tabular}



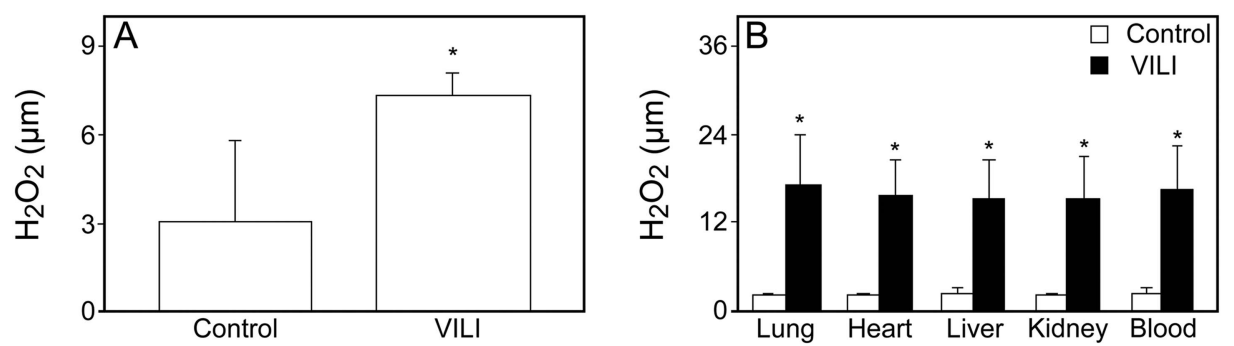

Fig. 1. A: High tidal volume $\left(V_{T}, 40 \mathrm{~mL} / \mathrm{kg}\right)$ ventilation for $6 \mathrm{~h}$ resulted in increased oxidant stress as detected by $\mathrm{H}_{2} \mathrm{O}_{2}$ production in the bronchoalveolar lavage fluid of the lung compared with the control group at low $\mathrm{V}_{\mathrm{T}}(6 \mathrm{~mL} / \mathrm{kg})$. B: Ventilator-induced lung injury (VILI) increased $\mathrm{H}_{2} \mathrm{O}_{2}$ levels in lung, heart, liver, and kidney tissues and arterial blood. ${ }^{*} P<.05$ compared with the control group. Data are presented as mean $\pm \mathrm{SD}$.
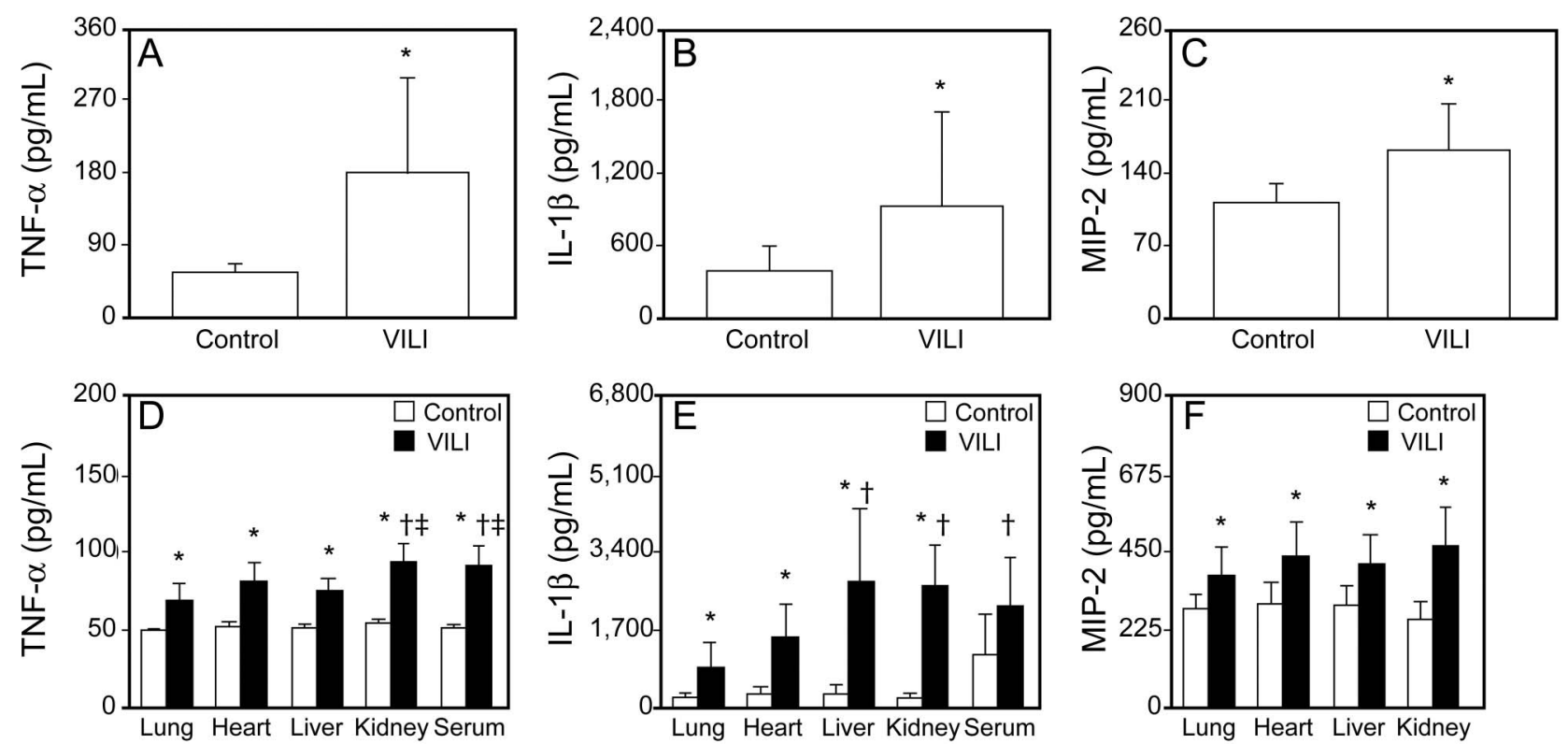

Fig. 2. High tidal volume $\left(\mathrm{V}_{\mathrm{T}}, 40 \mathrm{~mL} / \mathrm{kg}\right)$ ventilation for $6 \mathrm{~h}$ induced increased expression of pro-inflammatory cytokines, including tumor necrosis factor alpha (TNF- $\alpha)(\mathrm{A})$, interleukin-1 $\beta$ (IL-1 $\beta)(\mathrm{B})$, and macrophage inflammatory protein-2 (MIP-2) (C), in the bronchoalveolar lavage fluid of the lung compared with the control group at low $V_{T}(6 \mathrm{~mL} / \mathrm{kg})$. High $V_{T}$ ventilation for $6 \mathrm{~h}$ induced up-regulation of pro-inflammatory cytokines, including tumor necrosis factor alpha (D), IL-1 $\beta(E)$, and MIP-2 (F), in lung, heart, liver, and kidney tissues and also up-regulation of IL-1 $\beta$ and tumor necrosis factor alpha in arterial blood. ${ }^{*} P<.05$ compared with the control group. $† P<.05$ compared to lung tissue with ventilator-induced lung injury (VILI). $\ddagger P<.05$ compared to liver tissue with VILI. Data are presented as mean \pm SD.

tissues (Fig. 2D), and the IL-1 $\beta$ levels in serum and kidney and liver tissues were higher than those in lung tissues (Fig. 2E). The MIP-2 levels in lung, heart, liver, and kidney tissues in the VILI group were higher than those in the control group (Fig. 2F). These data demonstrated that volutrauma could augment the release of pro-inflammatory cytokines from the lungs into the systemic circulation and was associated with increased inflammation of the distal organs. However, cytokines appeared to be differentially expressed in extrapulmonary organs in this animal model of VILI. The expression of tumor necrosis factor alpha in rats receiving high $V_{T}$ ventilation was significantly higher in kidney tissue (Fig. 2D), and that of IL-1 $\beta$ was higher in liver and kidney tissues (Fig. 2E).

\section{Histopathological Changes in VILI}

The lung histology of VILI was characterized by perivascular edema, interstitial and intra-alveolar leukocyte infiltration, and marked heterogeneity in alveolar inflation (Fig. 3B). The pathologic score of lung injury in rats with high $\mathrm{V}_{\mathrm{T}}$ ventilation was significantly increased compared with that in the control group (Fig. 3C).

\section{Apoptosis}

The levels of caspase-3 in lung, heart, liver, and kidney tissues in the VILI group were higher than those in the control group (Fig. 4A). There were no significant differ- 

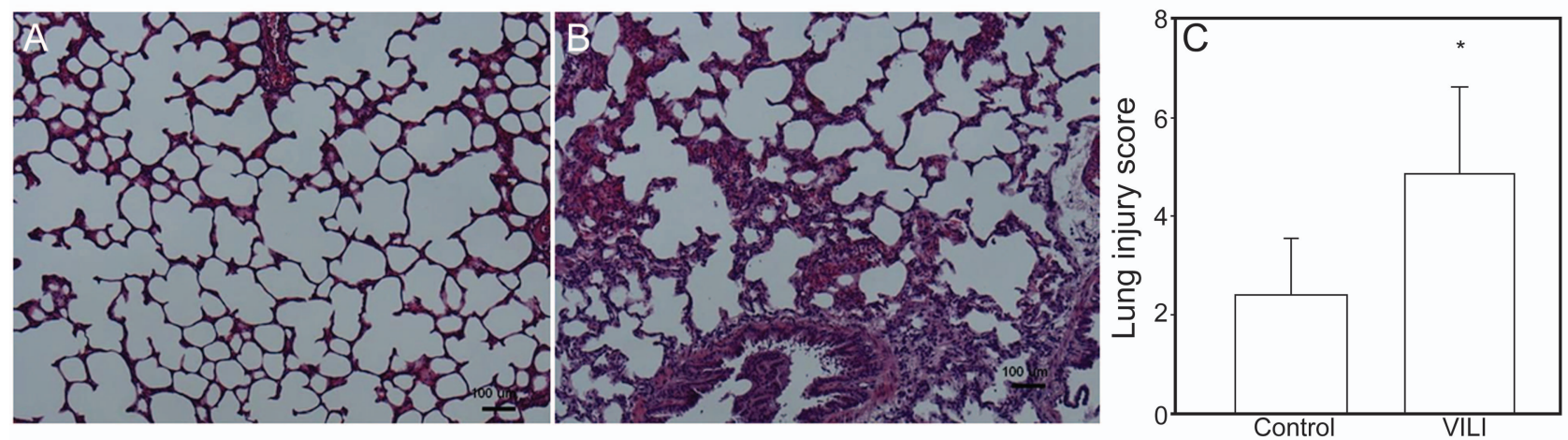

Fig. 3. Pathologic changes (A and B) and total lung injury score (C) of ventilator-induced lung injury (VILI) by high tidal volume ventilation presented as perivascular edema, intra-alveolar hemorrhage and congestion, and interstitial and intra-alveolar leukocyte infiltration. Lung tissue with hematoxylin and eosin stain is shown at $\times 200$ magnification. ${ }^{*} P<.05$ compared with the control group. Data are presented as mean $\pm \mathrm{SD}$.

A
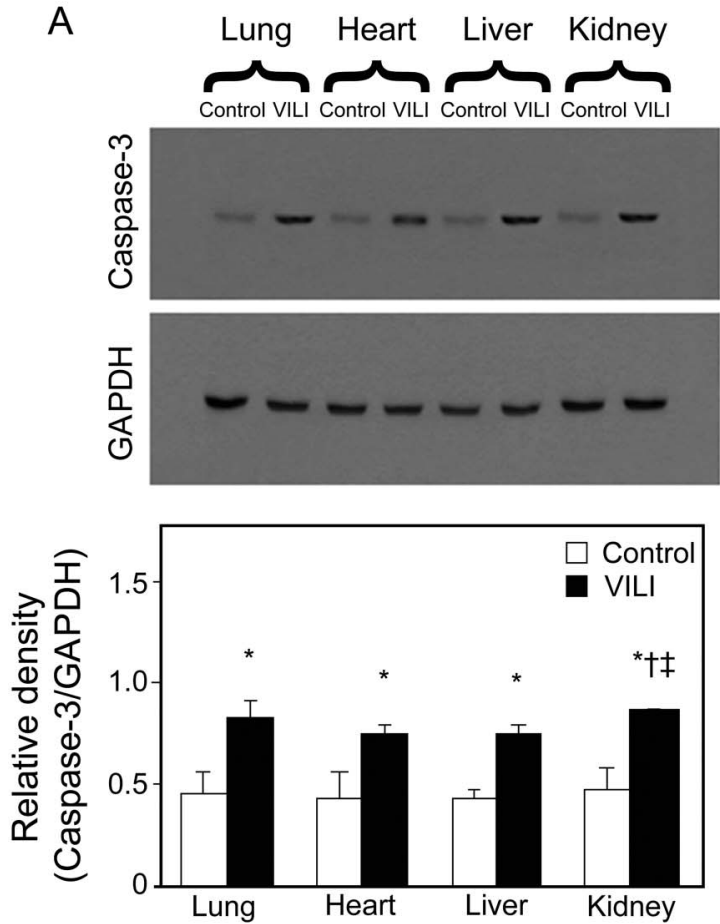

B
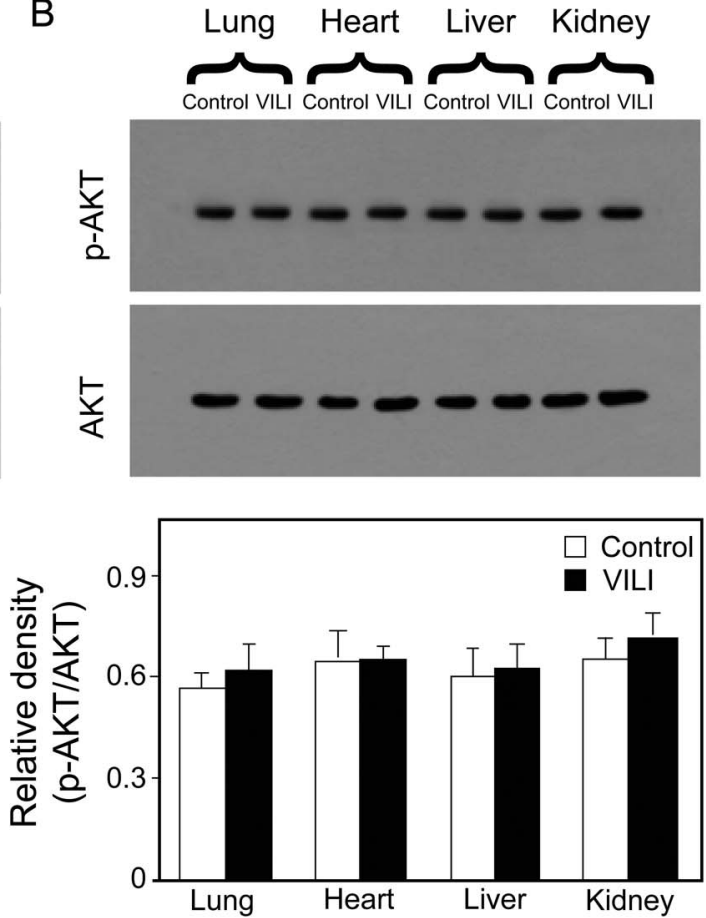

Fig. 4. High tidal volume $\left(\mathrm{V}_{T}\right)$ ventilation induced activation of caspase-3 in the lung, heart, liver, and kidney, but not AKT phosphorylation. A: High $V_{T}(40 \mathrm{~mL} / \mathrm{kg})$ ventilation for $6 \mathrm{~h}$ induced activation of caspase-3 in heart, liver, and kidney tissues compared with the control group at low $\mathrm{V}_{\mathrm{T}}(6 \mathrm{~mL} / \mathrm{kg})$, and the level of caspase-3 activity was higher in kidney tissue than in heart and liver tissues. B: Conversely, there were no significant differences in AKT phosphorylation between the high $\mathrm{V}_{\mathrm{T}}$ and control groups in lung, heart, liver, and kidney tissues. ${ }^{*} P<.05$ compared with the control group. $\dagger P<.05$ compared with heart tissue with ventilator-induced lung injury (VILI). $¥ P<.05$ compared with liver tissue with VILI. AKT = serine/threonine protein kinase B; p-AKT = phosphorylated AKT; GAPDH = glyceraldehyde-3-phosphate dehydrogenase. Data are shown as mean $\pm \mathrm{SD}$.

ences in phosphorylated AKT activation in lung, heart, liver, and kidney tissues in the VILI group compared with the control group (Fig. 4B). These results indicate that VILI induced apoptosis in lung, heart, liver, and kidney tissues associated with caspase-3 activation, but not via the AKT pathway. Greater levels of apoptosis were found in lung, heart, liver, and kidney tissues in the VILI group compared with the control group (Fig. 5). The apoptotic score in kidney tissue was higher than that in heart and liver tissues (Fig. 6).

\section{MAPK and NF-KB}

High $\mathrm{V}_{\mathrm{T}}$ ventilation resulted in up-regulation of JNK, p38 MAPK, and NF-KB in lung, heart, liver, and kidney 


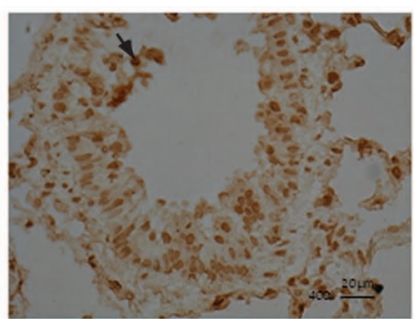

Control Lung

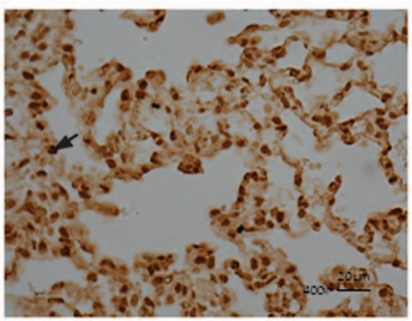

VILI Lung

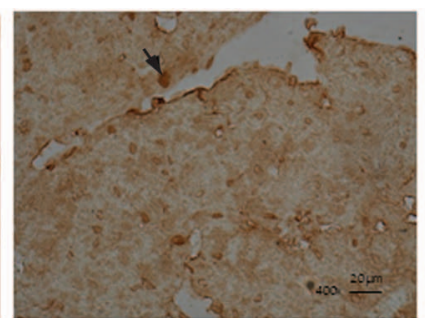

Control Heart

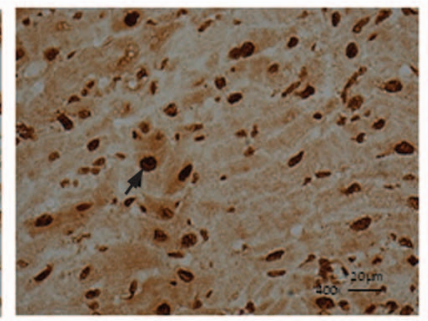

VILI Heart

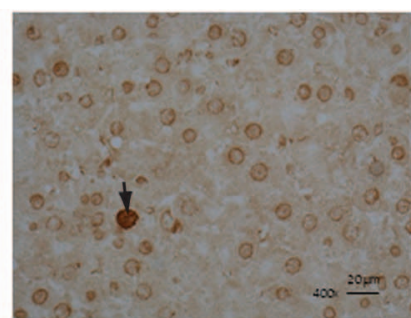

Control Liver

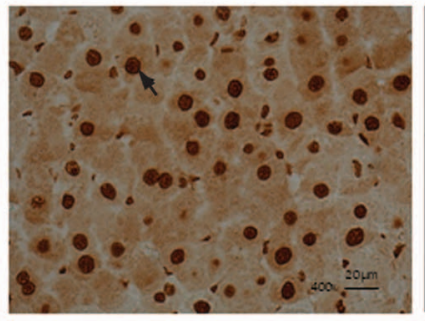

VILI Liver

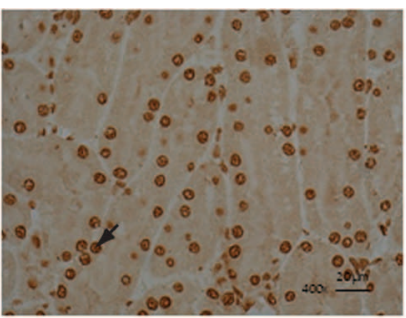

Control Kidney

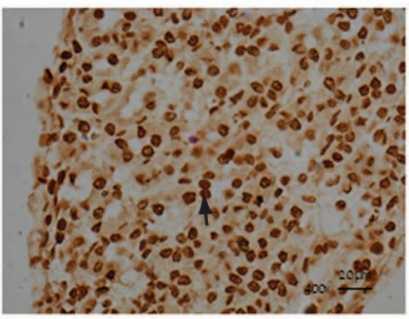

VILI Kidney

Fig. 5. High tidal volume $\left(\mathrm{V}_{\mathrm{T}}, 40 \mathrm{~mL} / \mathrm{kg}\right)$ ventilation for $6 \mathrm{~h}$ induced significant cellular apoptosis in lung, heart, liver, and kidney tissues as measured by terminal deoxynucleotidyl transferase dUTP nick end labeling stain in ventilator-induced lung injury (VILI) groups compared with control groups at low $\mathrm{V}_{\mathrm{T}}(6 \mathrm{~mL} / \mathrm{kg})$. Representative examples of dark brownish immunohistochemical staining for apoptosis are indicated by arrows (magnification, $\times 400$ ).

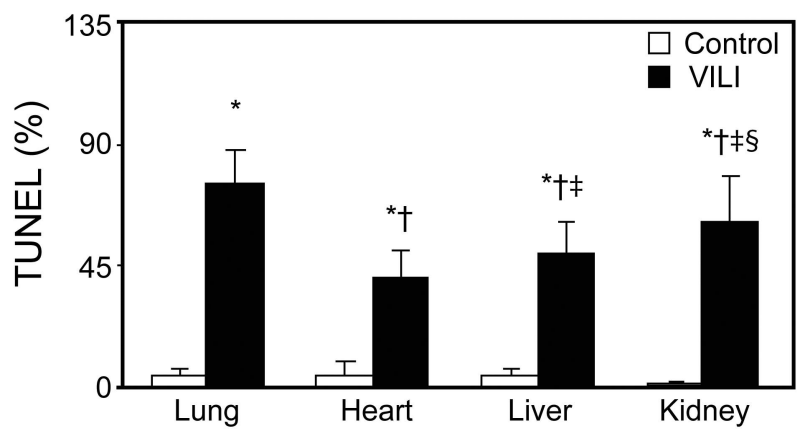

Fig. 6. The amount of apoptosis is expressed as the percentage of positively stained cells in the different organs. The kidney had the highest index of apoptotic percentage among all extrapulmonary organs. ${ }^{*} P<0.05$ compared with the control group. $\dagger P<0.05$ compared with lung tissue with ventilator-induced lung injury (VILI). $\ddagger P<0.05$ compared with heart tissue with VILI. § $P<0.05$ compared with liver tissue with VILI. TUNEL $=$ terminal deoxynucleotidyl transferase dUTP nick end labeling. Data are shown as mean \pm SD.

tissues. In contrast, high $\mathrm{V}_{\mathrm{T}}$ ventilation did not activate the ERKs by phosphorylation in lung, heart, liver, and kidney tissues (Fig. 7).

\section{Discussion}

In ARDS, mechanical ventilation can be a life-saving treatment. However, even with low $\mathrm{V}_{\mathrm{T}}$ ventilation, positive pressure deforms cells, inducing mechanotransduction with release of mediators (biotrauma), as well as volutrauma associated with uneven distribution of ventilation. ${ }^{20}$

\section{Mechanical Ventilation With High $\mathbf{V}_{T}$ Results in VILI}

Our results that show VILI causes lung injury, with lung histology characterized by pulmonary edema, interstitial and intra-alveolar leukocyte infiltration, and marked heterogeneity in alveolar inflation, consistent with previous studies. ${ }^{7-11,18}$ Our results further show that up-regulation of JNK, p38 MAPK, NF-KB, and caspase-3 is associated with inflammation and apoptosis in VILI; up-regulation of ERK is not associated with VILI.

\section{Up-Regulation of Cytokines and Reactive Oxygen Species in BALF, Lung Tissue, and Blood from the Left Ventricle}

Whether VILI per se can cause a significant release of pro-inflammatory cytokines is still undetermined. Several studies failed to show an increase in tumor necrosis factor alpha or IL-1 $\beta$ concentration in BALF or plasma after injurious ventilation strategies. ${ }^{19,21}$ On the other hand, some VILI studies, including our own, were able to demonstrate elevated levels of pro-inflammatory cytokines in BALF $22-26$ and blood. ${ }^{26}$ Furthermore, our results are the first to show up-regulation of $\mathrm{H}_{2} \mathrm{O}_{2}$ in BALF, lung tissue, and blood from the left ventricle, supporting a previous study showing a significant increase in serum isoprostane in rats ventilated with high $\mathrm{V}_{\mathrm{T}}$ compared with low $\mathrm{V}_{\mathrm{T}} \cdot{ }^{27}$ 
A
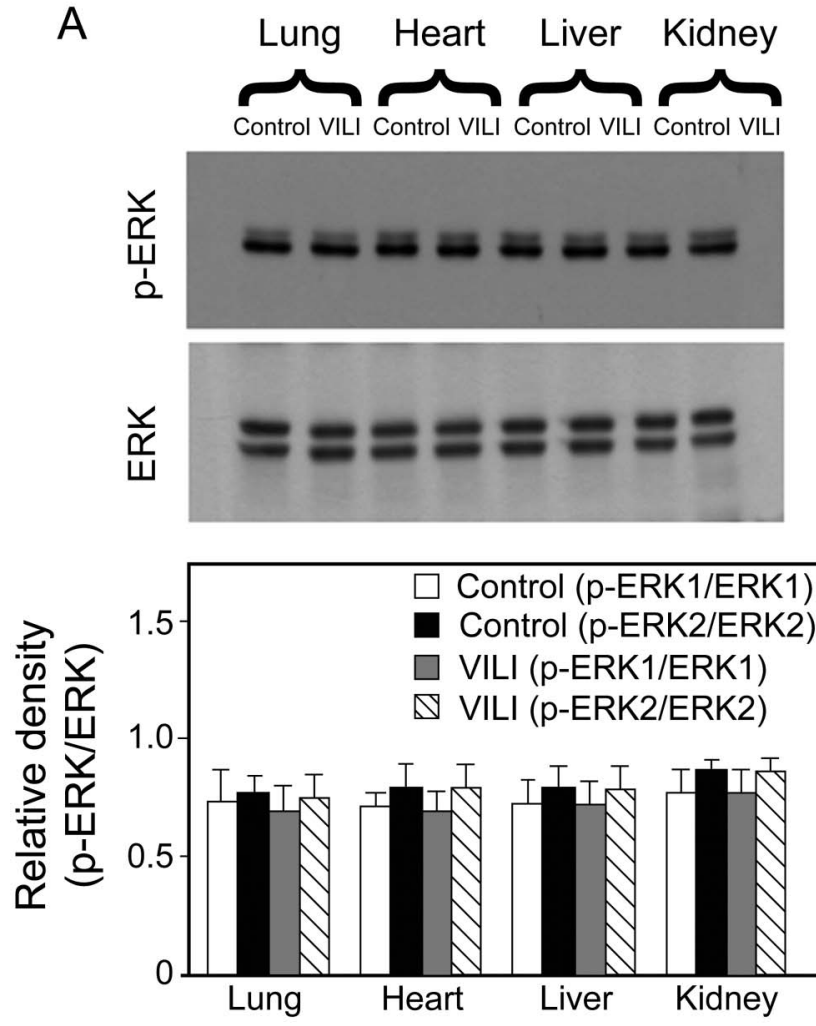

C
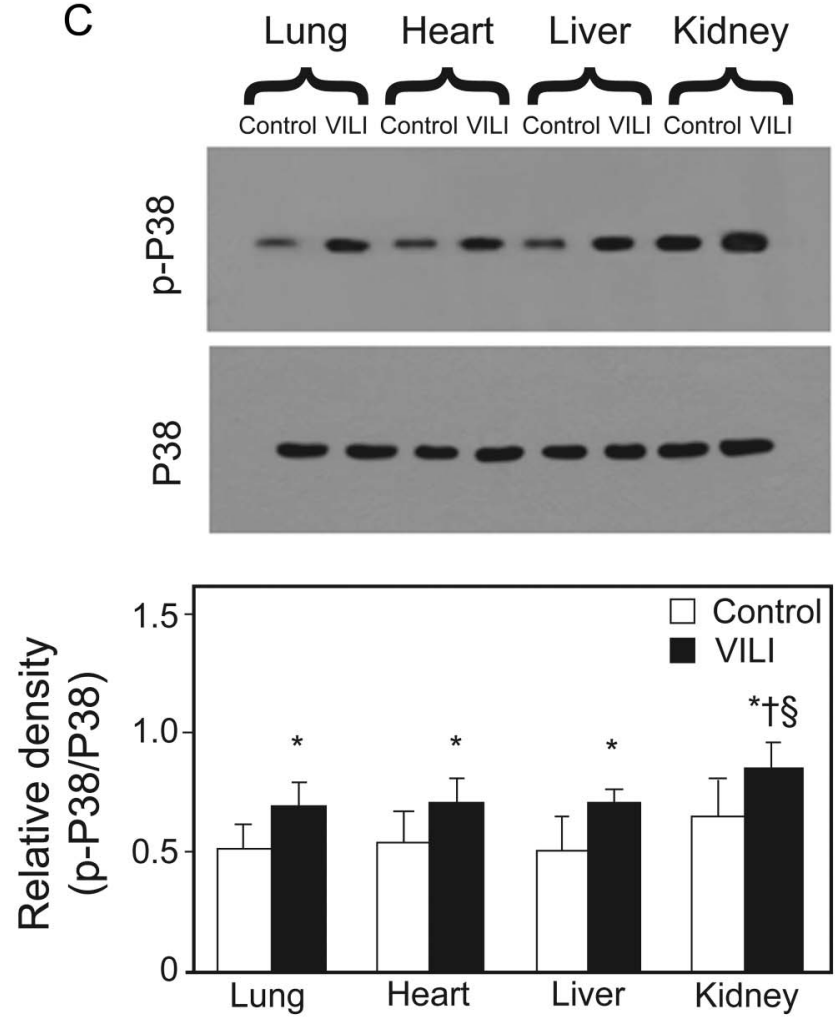

B
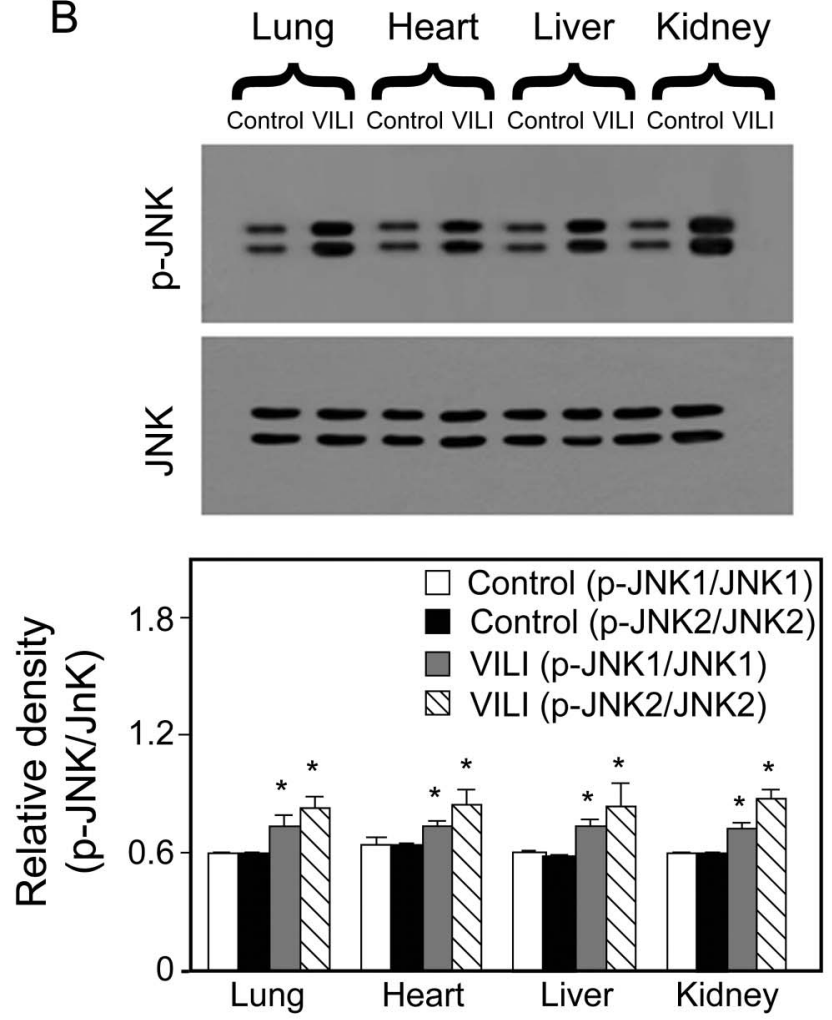

D
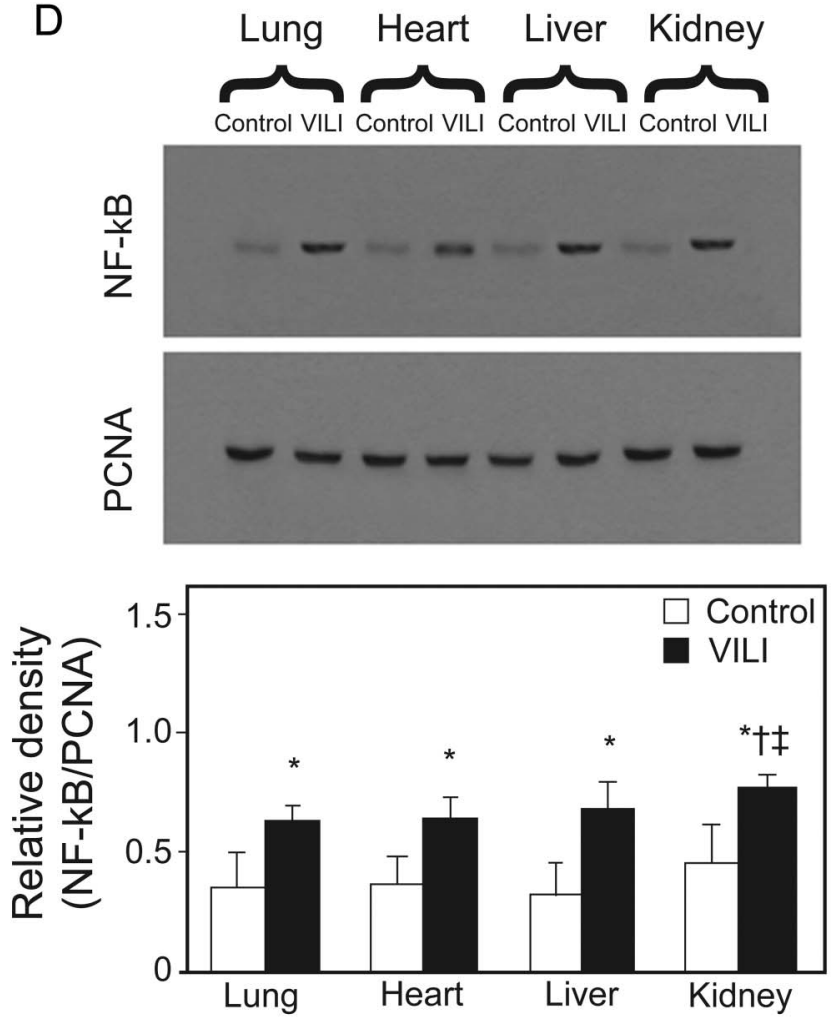

Fig. 7. High tidal volume $\left(\mathrm{V}_{\mathrm{T}}, 40 \mathrm{~mL} / \mathrm{kg}\right)$ ventilation for $6 \mathrm{~h}$ induced activation of c-Jun $\mathrm{N}$-terminal kinase (JNK), p38 mitogen-activated protein kinase, and nuclear factor kappa B (NF-KB) in lung, heart, liver, and kidney tissues (B-D). In contrast, extracellular signal-regulated kinase $(\mathrm{ERK})$ was not activated by high $\mathrm{V}_{\mathrm{T}}$ ventilation in all organs $(\mathrm{A})$. ${ }^{*} P<.05$ compared with the control group. $\dagger P<.05$ compared with lung tissue with ventilator-induced lung injury (VILI). $¥ P<.05$ compared with heart tissue with VILI. $§ P<.05$ compared with liver tissue with VILI. PCNA = proliferating cell nuclear antigen. Data are shown as mean \pm SD. 
Spillover of Cytokines and Reactive Oxygen Species in VILI Is Associated With Inflammation and Apoptosis in Distal Organs

We elucidated, for the first time, the potential molecular mechanism in the multiple organ involvement (heart, liver, and kidney) associated with VILI by demonstrating upregulation of JNK, p38 MAPK, NF-KB, tumor necrosis factor alpha, IL-1 $\beta$, MIP-2, and $\mathrm{H}_{2} \mathrm{O}_{2}$ and apoptosis in lung, heart, liver, and kidney tissues. We also demonstrated that extrapulmonary organs have individual biochemical responses to circulating soluble inflammatory cytokines and $\mathrm{H}_{2} \mathrm{O}_{2}$ from injured lungs that may lead to varying degrees of inflammation and apoptosis in distal organs. Among these distal organs (heart, liver, and kidney), the kidney appears to be more vulnerable to VILI.

A few studies have examined the relationship between VILI and distal organ involvement in animal models. The results from these prior studies can be summarized as follows: ventilator-induced up-regulation of adhesion molecules and myeloperoxidase in mouse lung, liver, and kidney tissues, ${ }^{28}$ increased endothelial nitric oxide synthase expression in lung and kidney tissues with high $\mathrm{V}_{\mathrm{T}}$ ventilation in rats, ${ }^{29}$ and association of VILI with an increase in gut permeability in a rat model. ${ }^{30}$ Our results show that VILI induced apoptosis not only in the lungs but also in the heart, liver, and kidneys, which is associated with upregulation of caspase-3. Apoptosis in the liver was greater that in the heart; furthermore, the kidneys showed greater apoptosis compared with the heart or liver. To our knowledge, no previous study has demonstrated apoptosis in distal organs in VILI, and only one study showed ventilator-induced airway epithelial cell apoptosis. ${ }^{28}$ However, a 2-hit (VILI [high $\mathrm{V}_{\mathrm{T}}$ ] + acid aspiration lung injury [intratracheal hydrochloric acid]) rabbit lung injury model was associated with epithelial cell apoptosis in the kidneys and small intestine. ${ }^{31}$

\section{Mechanisms Underlying VILI-Associated Multiple Organ Involvement and Differential Responses of Distal Organs}

The mechanisms underlying the relationship between VILI and multiple organ involvement are still unclear. It has long been known that mechanical ventilation has an impact on hemodynamics that could potentially lead to multiple organ failure. Recent studies suggest additional mechanisms by which mechanical ventilation for acute respiratory failure and associated biotrauma can impact extrapulmonary organs. ${ }^{14,15}$ In our animal model, there was no significant change in hemodynamics. On the basis of our results, we propose that the spillover of soluble cytokines and reactive oxygen species from the lungs into the circulation in VILI could cause inflammation and apoptosis in distal organs.

Our results show that high $\mathrm{V}_{\mathrm{T}}$ ventilation increased tissue tumor necrosis factor alpha protein expression in kidney tissue and blood to a greater level than in lung and liver tissues, that IL- $1 \beta$ expression in kidney and liver tissues was higher than in lung tissue, and that apoptosis in kidney tissue was more severe than in heart and liver tissues. These results suggest that extrapulmonary organs have differential responses to injury associated with VILI. Regarding the mechanism of injury relating VILI to downstream organs, Patterson et $a^{32}$ showed that exposure of mouse liver endothelial cells to lung-derived mediators during mechanical ventilation resulted in significant cytokine production via NF-KB. Moreover, previous studies proposed a possible mechanism by which mechanical ventilation may induce acute renal failure mediated by alveolar stretch-induced pulmonary inflammatory reaction with systemic release of mediators. ${ }^{33,34}$ Our findings are in agreement with previous results showing that several circulating cytokines, including tumor necrosis factor alpha, IL-1 $\beta$, and IL-8 (MIP-2), which can result in acute renal failure, are increased during mechanical ventilation in animal and human studies. ${ }^{34,35}$ In addition, renal failure is the most prevalent organ dysfunction associated with VILI in patients with ARDS. ${ }^{35}$ Thus, a possible specific susceptibility or autoregulation of different organs due to endothelial activation $^{28}$ and the complex interactions of several inflammatory mediators may contribute to the development of ventilator-induced distal organ injury. ${ }^{36}$

There are some limitations of this study. First, VILI was induced in healthy rats by $6 \mathrm{~h}$ of high $\mathrm{V}_{\mathrm{T}}$ ventilation. The ventilation parameters used in this study, although higher than those used clinically in humans, would have induced a moderately high degree of lung stretch in healthy rodents, as rodent lungs are much more compliant than human lungs. ${ }^{37} \mathrm{~A}$ recent study demonstrated that $\mathrm{V}_{\mathrm{T}}$ of up to only $40 \mathrm{~mL} / \mathrm{kg}$ induced substantial increases in both inflammation and pulmonary edema in rodents, consistent with development of acute lung injury. ${ }^{38}$ In clinical practice, mechanical ventilation in ARDS consists of applying a low $\mathrm{V}_{\mathrm{T}}$ for a longer duration. However, due to uneven distribution of ventilation, some alveoli are still overstressed, and both volutrauma (mechanotransduction due to deformed macrophages or structural cells in lungs) and biotrauma may be induced by positive-pressure ventilation. Second, this pure VILI model oversimplifies the clinical scenario of more complicated etiologies associated with respiratory failure such as ARDS or sepsis with multiple organ failure. Nevertheless, this animal model can provide insights into mechanisms by which mechanical ventilation can harm extrapulmonary organs by eliminating confounding factors such as bacterial toxins, gastric juice aspiration, and hyperoxia exposure encountered clin- 


\section{VILI-Associated Inflammation and Apoptosis in Distal ORgans}

ically. Third, in our experiments, the amount of blood obtained from the left ventricle was not sufficient to assay for an extensive panel of cytokines and mediators. In addition, it is technologically difficult to sample the arterial blood from every distal organ. Further study is needed to identify other circulating soluble mediators that might contribute to biotrauma of VILI in triggering multiple organ injury, including studies based on genomics, metabolomics, proteomics, and micro-ribonucleic acids.

\section{Conclusions}

High $\mathrm{V}_{\mathrm{T}}$ ventilation induces VILI and is associated with inflammation and apoptosis in distal organs. Up-regulation of reactive oxygen species and cytokines in VILI is associated with systemic inflammatory responses. The kidney appears to be more vulnerable to VILI-associated systemic effects compared with the heart and liver.

We propose that systemic inflammation may induce more cytokines and reactive oxygen species that are circulated back to the lungs, which augments lung injury. Clear elucidation of the mechanisms involved in VILI and distal organ damage would be beneficial for the development of novel therapeutic strategies to improve the outcome of ARDS. Strategies for blocking this vicious cycle between VILI and multiple organ involvement are urgently needed to decrease the mortality rate of ARDS.

\section{REFERENCES}

1. The Acute Respiratory Distress Syndrome Network. Ventilation with lower tidal volumes as compared with traditional tidal volumes for acute lung injury and the acute respiratory distress syndrome. N Engl J Med 2000;342(18):1301-1308.

2. Ferguson ND, Frutos-Vivar F, Esteban A, Anzueto A, Alía I, Brower $\mathrm{RG}$, et al. Airway pressures, tidal volumes, and mortality in patients with acute respiratory distress syndrome. Crit Care Med 2005;33(1): 21-30.

3. Montgomery AB, Stager MA, Carrico CJ, Hudson LD. Causes of mortality in patients with adult respiratory distress syndrome. Am Rev Respir Dis 1985;132(3):485-489.

4. Stapleton RD, Wang BM, Hudson LD, Rubenfeld GD, Caldwell ES, Steinberg KP. Causes and timing of death in patients with ARDS. Chest 2005;128(2):525-532.

5. Suchyta MR. The changing face of organ failure in ARDS. Chest 2003;124(5):1871-1879.

6. Slutsky AS, Tremblay LN. Multiple system organ failure: Is mechanical ventilation a contributing factor? Am J Respir Crit Care Med 1998;157(6):1721-1725.

7. Dreyfuss D, Soler P, Basset G, Saumon G. High inflation pressure pulmonary edema: respective effects of high airway pressure, high tidal volume, and positive end-expiratory pressure. Am Rev Respir Dis $1988 ; 137(5): 1159-1164$.

8. dos Santos CC, Slutsky AS. The contribution of biophysical lung injury to the development of biotrauma. Annu Rev Physiol 2006; 68):585-618.

9. Uhlig U, Haitsma JJ, Goldmann T, Poelma DL, Lachmann B, Uhlig $\mathrm{S}$. Ventilation-induced activation of the mitogen-activated protein kinase pathway. Eur Respir J 2002;20(4):946-956.
10. Wilson MR, Choudhury S, Goddard ME, O'Dea KP, Nicholson AG, Takata M. High tidal volume upregulates intrapulmonary cytokines in an in vivo mouse model of ventilator-induced lung injury. J Appl Physiol 2003;95(4):1385-1393.

11. Chiang CH, Chuang CH, Liu SL, Lee TS, Kou YR, Zhang H. Apocynin attenuates ventilator-induced lung injury in an isolated and perfused rat lung model. Intensive Care Med 2011;37(8):1360-1367.

12. Bilali A, Kurata S, Ikeda S, Georgieva GS, Zhu C, Tomita M, et al. Lung-lung interaction in isolated perfused unilateral hyperventilated rat lungs. Transl Res 2010;155(5):228-237.

13. Plötz FB, Slutsky AS, van Vught AJ, Heijnen CJ. Ventilator-induced lung injury and multiple system organ failure: a critical review of facts and hypotheses. Intensive Care Med 2004;30(10):1865-1872.

14. Del Sorbo L, Slutsky AS. Acute respiratory distress syndrome and multiple organ failure. Curr Opin Crit Care 2011;17(1):1-6.

15. Jaecklin T, Otulakowski G, Kavanagh B. Do soluble mediators cause ventilator-induced lung injury and multi-organ failure? Intensive Care Med 2010;36(5):750-757.

16. Kuebler WM. From a distance: ventilation-dependent extra-pulmonary injury. Transl Res 2010;155(5):217-219.

17. Ciesla DJ, Moore EE, Johnson JL, Burch JM, Cothren CC, Sauaia A. The role of the lung in post-injury multiple organ failure. Surgery 2005;138(4):749-757; discussion 757-758.

18. Liu YY, Lee CH, Dedaj R, Zhao H, Mrabat H, Sheidlin A, et al High-molecular-weight hyaluronan-a possible new treatment for sepsis-induced lung injury: a preclinical study in mechanically ventilated rats. Crit Care 2008;12(4):R102.

19. Chiang CH, Pai HI, Liu SL. Ventilator-induced lung injury (VILI) promotes ischemia/reperfusion lung injury (I/R) and NF-KB antibody attenuates both injuries. Resuscitation 2008;79(1):147-154.

20. Slutsky AS. Ventilator-induced lung injury: from barotrauma to biotrauma. Respir Care 2005;50(5):646-659.

21. Haitsma JJ, Uhlig S, Göggel R, Verbrugge SJ, Lachmann U, Lachmann B. Ventilator-induced lung injury leads to loss of alveolar and systemic compartmentalization of tumor necrosis factor-alpha. Intensive Care Med 2000;26(10):1515-1522.

22. Kotani M, Kotani T, Li Z, Silbajoris R, Piantadosi CA, Huang YC. Reduced inspiratory flow attenuates IL- 8 release and MAPK activation of lung overstretch. Eur Respir J 2004;24(2):238-246.

23. Tremblay L, Valenza F, Ribeiro SP, Li J, and Slutsky AS. Injurious ventilatory strategies increase cytokines and c-fos m-RNA expression in an isolated rat lung model. J Clin Invest 1997;99(5):944-952.

24. Tremblay LN, Miatto D, Hamid Q, Govindarajan A, Slutsky AS. Injurious ventilation induces widespread pulmonary epithelial expression of tumor necrosis factor-alpha and interleukin-6 messenger RNA. Crit Care Med 2002;30(8):1693-1700.

25. Welk B, Malloy JL, Joseph M, Yao LJ, Veldhuizen AW. Surfactant treatment for ventilation-induced lung injury in rats: effects on lung compliance and cytokines. Exp Lung Res 2001;27(6):505-520.

26. Hoegl S, Boost KA, Flondor M, Scheiermann P, Muhl H, Pfeilschifter $\mathrm{J}$, et al. Short-term exposure to high-pressure ventilation leads to pulmonary biotrauma and systemic inflammation in the rat. Int J Mol Med 2008;21(4):513-519.

27. Syrkina O, Jafari B, Hales CA, Quinn DA. Oxidant stress mediates inflammation and apoptosis in ventilator-induced lung injury. Respirology 2008;13(3):333-340.

28. Hegeman MA, Hennus MP, Heijnen CJ, Specht PA, Lachmann B, Jansen NJ, et al. Ventilator-induced endothelial activation and inflammation in the lung and distal organs. Crit Care 2009;13(6):R182.

29. Choi WI, Quinn DA, Park KM, Moufarrej RK, Jafari B, Syrkina O, et al. Systemic microvascular leak in an in vivo rat model of ventilator-induced lung injury. Am J Respir Crit Care Med 2003;167(12): 1627-1632. 


\section{VILI-Associated Inflammation and Apoptosis in Distal ORgans}

30. Guery BP, Welsh DA, Viget NB, Robriquet L, Fialdes P, Mason $\mathrm{CM}$, et al. Ventilation-induced lung injury is associated with an increase in gut permeability. Shock 2003;19(6):559-563.

31. Imai Y, Parodo J, Kajikawa O, de Perrot M, Fischer S, Edwards V, et al. Injurious mechanical ventilation and end-organ epithelial cell apoptosis and organ dysfunction in an experimental model of acute respiratory distress syndrome. JAMA 2003;289(16):2104-2112.

32. Patterson EK, Yao LJ, Ramic N, Lewis JF, Cepinskas G, McCaig L, et al. Lung-derived mediators induce cytokine production in downstream organs via an NF-KB-dependent mechanism. Mediators Inflamm 2013;2013:586895.

33. Koyner JL, Murray PT. Mechanical ventilation and the kidney. Blood Purif 2010;29(1):52-68.
34. Kuiper JW, Groeneveld AB, Slutsky AS, Plötz FB. Mechanical ventilation and acute renal failure. Crit Care Med 2005;33(6):1408-1415.

35. Ranieri VM, Giunta F, Suter PM, Slutsky AS. Mechanical ventilation as a mediator of multisystem organ failure in acute respiratory distress syndrome. JAMA 2000;284(1):43-44.

36. Walker MG, Yao LJ, Patterson EK, Joseph MG, Cepinskas G, Veldhuizen RA, et al. The effect of tidal volume on systemic inflammation in acid-induced lung injury. Respiration 2011;81(4):333-342.

37. Soutiere SE, Mitzner W. On defining total lung capacity in the mouse. J Appl Phyiol 2004;96(5):1658-1664.

38. Wilson MR, Patel BV, Takata M. Ventilation with "clinically relevant" high tidal volumes does not promote stretch-induced injury in the lungs of healthy mice. Crit Care Med 2012;40(10):2850-2857. 